\title{
Cross-cultural comparison of sensory behaviors in children with autism.
}

Kristina G Caron

Scarborough School Department

Roseann C Schaaf

Teal W. Benevides

Thomas Jefferson University

Eynat Gal

University of Haifa

Follow this and additional works at: https://jdc.jefferson.edu/otfp

Part of the Occupational Therapy Commons

Let us know how access to this document benefits you

\section{Recommended Citation}

Caron, Kristina G; Schaaf, Roseann C; Benevides, Teal W.; and Gal, Eynat, "Cross-cultural comparison of sensory behaviors in children with autism." (2012). Department of Occupational Therapy Faculty Papers. Paper 50.

https://jdc.jefferson.edu/otfp/50

This Article is brought to you for free and open access by the Jefferson Digital Commons. The Jefferson Digital Commons is a service of Thomas Jefferson University's Center for Teaching and Learning (CTL). The Commons is a showcase for Jefferson books and journals, peer-reviewed scholarly publications, unique historical collections from the University archives, and teaching tools. The Jefferson Digital Commons allows researchers and interested readers anywhere in the world to learn about and keep up to date with Jefferson scholarship. This article has been accepted for inclusion in Department of Occupational Therapy Faculty Papers by an authorized administrator of the Jefferson Digital Commons. For more information, please contact: JeffersonDigitalCommons@jefferson.edu. 


\title{
BRIEF REPORT
}

\section{Cross-Cultural Comparison of Sensory Behaviors in Children With Autism}

\author{
Kristina G. Caron, Roseann C. Schaaf, Teal W. Benevides, Eynat Gal
}

KEY WORDS

- autistic disorder

- child behavior

- cross-cultural comparison

- environment

- sensation
Kristina G. Caron, MS, OTR/L, is Occupational Therapist, Department of Occupational Therapy, Scarborough School Department, Eight Corners School, 22 Mussey Road, Scarborough, ME 04074; kcaron@scarborough.k12.me.us. At the time of this study, she was a graduate student in the Department of Occupational Therapy, Thomas Jefferson University, Philadelphia.

Roseann C. Schaaf, PhD, OTR/L, FAOTA, is Professor and Vice Chair, Department of Occupational Therapy, Jefferson School of Health Professions, and Faculty, Farber Institute for Neurosciences, Thomas Jefferson University, Philadelphia.

Teal W. Benevides, MS, OTR/L, is Assistant Professor, Sensory Integration Lab Coordinator, Department of Occupational Therapy, Jefferson School of Health Professions, Thomas Jefferson University, Philadelphia.

Eynat Gal, PhD, OTR, is Lecturer, Occupational Therapy Department, Faculty of Social Welfare and Health Sciences, University of Haifa, Haifa, Israel.

Parents of children with autism frequently report that their children exhibit unusual responses to sensory experiences. Little research is available, however, describing how parents' and children's culture and environment might influence parents' reports of their children's behaviors. This study compared the frequency of parent-reported responses to sensory experiences in children from two countries-Israel and the United States. We administered the Short Sensory Profile to primary caregivers of children with autism spectrum disorders (ASD) and typically developing peers. Results indicate that Israeli parents reported unusual responses to sensory experiences less frequently than U.S. parents for both ASD and typically developing children. U.S. children with ASD demonstrated significantly greater difficulty in the Auditory Filtering and Visual/Auditory Sensitivity domains than Israeli children with ASD. These findings indicate a need to further explore the influence of culture and environment on caregiver perceptions of the responses to sensory experiences of children with ASD.

Caron, K. G., Schaaf, R. C., Benevides, T. W., \& Gal, E. (2012). Brief Report-Cross-cultural comparison of sensory behaviors in children with autism. American Journal of Occupational Therapy, 66, e77-e80. http://dx.doi.org/ 10.5014/ajot.2012.004226

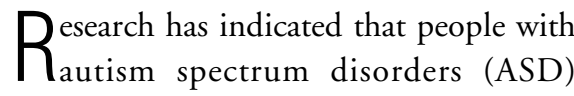
process sensory information differently from others (Bennett, 1996; Brock, Brown, Boucher, \& Rippon, 2002; Frith, 2003; Mottron, Burack, Stauder, \& Robaey, 1999; Ornitz, 1974) and that 80\%-95\% of people with ASD experience unusual responses to sensory experiences. Sensory processing disorders in children with ASD have been described in the auditory, visual, tactile, gustatory, olfactory, kinesthetic, and proprioceptive systems (Kientz \& Dunn, 1997; Rogers, Hepburn, \& Wehner, 2003; Tomchek \& Dunn, 2007); such children have a high frequency of underresponsiveness and sensory avoiding behaviors and a low frequency of sensory seeking in comparison with typically developing peers (Ben-Sasson et al., 2007, 2008).

Research also suggests that neurological development, including sensory processing, is subject to environmental influences. For example, Gal, Dyck, and Passmore (2002) found that various sensory environments (i.e., aversive, neutral, and appetitive) may have a direct effect on behaviors such as stereotyped movements in children with ASD. Cermak and Daunhauer (1997) found that institutionalization can have an effect on responses to sensory experiences.

A person's culture influences values, interactions, social customs, and family structures, which help organize the environment in which he or she lives. The Occupational Therapy Practice Framework: Domain and Process (2nd ed.) defines culture as the "customs, beliefs, activity patterns, behavior standards, and expectations accepted by the society of which the client is a member" (American Occupational Therapy Association, 2008, p. 645). Evidence suggests that a person's cultural environment has an effect on many facets of development, illness, and behavior (Karno \& Jenkins, 1993), including expressed emotion (Kleinman, 1988; Lewis-Fernández, 1996) and the expression and experience of pain (Kirmayer, 2008). Culture also is hypothesized to play a role in the prevalence and risk and 
protective factors for some disorders (Canino \& Alegría, 2008).

Although people with neurological disorders, including ASD, might be expected to show similar symptoms across cultures, no data exist to show that this is the case. The purpose of this study was to examine differences in responses to sensory experiences in two countries-Israel and the United States. We compared agematched, typically developing children and children with ASD across the two cultures.

\section{Method}

\section{Participants}

The study's inclusion criteria required participants to be 5-12 yr old and either to be typically developing (no medical or psychological diagnoses) or to have an ASD diagnosis. Diagnosis of ASD was noted in participants' records according to criteria from the Diagnostic and Statistical Manual of Mental Disorders (4th ed.; American Psychiatric Association, 1994). Data were gathered from two separate datasets: one from the United States (an SPSS database from a large study on autism) and the other from Israel (an SPSS database from a large study on sensory processing in children with and without disabilities). Approval to conduct the study was granted through an interagency authorization agreement for data sharing from Thomas Jefferson University. Child participants from both datasets who met the current study's inclusion criteria were entered into one database for group comparison.

\section{Measures}

The Short Sensory Profile (SSP; McIntosh, Miller, Shyu, \& Dunn, 1999), the research version of the Sensory Profile (Dunn, 1999), is a 38-item caregiver questionnaire that assesses sensory processing abilities in children aged 3-11 yr. Items are scored on a fivepoint Likert scale, with $1=$ behavior is always observed and $5=$ behavior is never observed. Separate scores are calculated for seven sections: Tactile Sensitivity, Taste/ Smell Sensitivity, Movement Sensitivity, Underresponsive/Seeks Sensation, Auditory Filtering, Low Energy/Weak, and Visual/Auditory Sensitivity. A Total score provides a combined score. Internal reliability ranges from .70 to .90 and internal validity correlations from .25 to .76 (McIntosh et al., 1999). Construct validity was established by correlating SSP scores with abnormal physiological responses to a series of sensory challenges (Miller, Reisman, McIntosh, \& Simon, 2001). The U.S. version of the SSP has been formally translated into Hebrew and is widely used in Israel. Internal reliability of the SSP in 395 typically developing children in Israel was .92 (Engel-Yeger, 2010).

\section{Procedures}

Primary caregivers of child participants completed the SSP following the standardized procedures. Data were combined from both datasets and analyzed with SPSS Version 11.5 (SPSS, Inc., Chicago). SSP scores were converted to standardized $z$ scores using criteria developed by McIntosh et al. (1999). $Z$ scores above -1.00 indicate typical development, those from -1.00 to -2.00 indicate probable differences in the child's responses to sensory experiences, and those below -2.00 indicate definite differences in the child's responses to sensory experiences. Independent two-tailed $t$ tests were used to evaluate differences between typical participants and those with ASD in the two cultures. The criterion for statistical significance was set at .05 for all results in the study.

\section{Results}

Our sample included 54 typically developing participants (28 from Israel, 26 from the United States) and 57 participants with ASD (37 from Israel, 20 from the United States). No significant differences were found in age, $F(3,107)=$ $1.76, p>.05$, or gender, $\chi^{2}(1, N=54)=$ $0.30, p>.05$, across the two countries. Significantly more boys than girls were in both the U.S. and the Israeli groups, $\chi^{2}(1$, $N=111)=7.70, p<.005$, but the frequency of boys or girls included did not differ across countries, $\chi^{2}(1, N=57)=$ $0.49, p>.05$. Comparison of mean scores of participants with ASD from the United States and Israel yielded significant differences in Auditory Filtering, $t(55)=$ $2.21, p<.05$, and Visual/Auditory Sen- sitivity, $t(55)=4.53, p<.001$, with participants from Israel scoring higher (indicating fewer sensory symptoms). Notably, children with ASD from both countries scored lower than -1.00 on most subtests.

For typically developing participants, significant differences were found between the groups on Tactile Sensitivity, $t(52)=$ 2.26, $p<.05$; Underresponsive/Seeks Sensation, $t(52)=3.8, p<.001$; Auditory Filtering, $t(52)=3.66, p<.001$; and Visual/Auditory Sensitivity, $t(52)=3.87$, $p<.001$, as well as on the Total score, $t(52)=$ $3.52, p<.001$. Mean scores of typically developing participants from Israel were higher than those from the United States on all sections (indicating better ratings on the SSP).

\section{Discussion}

Examination of SSP scores in typically developing participants from both cultures provides perspective for comparing participants with ASD across these cultures. As expected, all $z$ scores for typically developing participants in both countries fell within normal ranges; however, typically developing participants from Israel scored higher on all sections and significantly higher on four of the seven sections and on the Total score. This finding suggests that fewer caregivers reported unusual responses to sensory experiences for Israeli participants. In light of findings that U.S. SSP scores are reliable for the Israeli population (Engel-Yeger, 2010), these differences suggest either that typically developing participants in Israel may not respond behaviorally to sensory experiences as intensely as typically developing children in the United States or that Israeli caregivers are less likely to rate a response to a sensory experience as "significantly different" than usual.

Participants in both ASD samples demonstrated more unusual responses to sensory experiences than the typically developing comparison groups. This finding is consistent with the literature (Gal, Cermak, \& Ben-Sasson, 2007; Rogers et al., 2003; Tomchek \& Dunn, 2007) and adds further evidence that children with ASD have significantly more unusual responses to sensory experiences. Of particular interest, 
Israeli caregiver reports rated the children with ASD as having better auditory filtering and fewer problems with visual/auditory sensitivity than did U.S. caregiver reports. This finding warrants further investigation to determine whether it is related to cultural differences influencing the caregivers' reports (i.e., do Israeli caregivers have a different cultural standard for auditory filtering and visual/ auditory sensitivity than U.S. caregivers?) or to actual population differences (do children from different geographic areas or different cultures exhibit differences in sensory performance?).

One way to consider our findings is to look at the results using Super and Harkness's (2002) developmental niche framework. This framework suggests that by organizing a child's environment, culture is a factor that shapes the course of child development. A child's developmental niche comprises three operational subsystems: (1) the physical and social settings, (2) the historically constituted customs and practices of child care and child rearing, and (3) the psychology of caretakers. The interaction of these subsystems creates a specific cultural developmental niche that organizes a child's daily environment and thus influences development.

Applying this framework to the findings of our study, one would expect the participants from each culture to have different developmental niches that subsequently influence the child's development. As a descriptive study, our findings only suggest that differences may exist between cultures; further investigation of the aspects of the developmental niche, the child, and the interactions between them is warranted to understand cultural differences in sensory processing. The developmental niche framework is also useful in supporting assessment of context-specific cultural aspects that may affect the interpretation of assessment findings, including assessments of sensory processing.

\section{Implications for Occupational Therapy Practice}

The results of this study have the following implications for occupational therapy practice:
- When planning and providing intervention for children with ASD and other disabilities, therapists need to be mindful of the influence of culture on their sensory processing.

- When using assessments that examine sensory processing on the basis of parentreported responses to sensory experiences cross-culturally, therapists need to consider the impact of culture and environment when interpreting results.

\section{Conclusion}

Although the findings from this study yield important information about cultural differences in sensory processing, the findings must be interpreted with caution because of several limitations of the study. Convenience samples were used for both the U.S. and the Israeli groups; thus, the sample may not be representative of the population of children with ASD in these countries. Second, the sample sizes of the ASD groups were discrepant (37 participants from Israel, 20 from the United States); this difference may have had an impact on findings. Finally, the sample of participants with ASD from both countries was selected on the basis of chart diagnosis from the respective referral sites. It is possible that the criteria, assessments, and cut scores were different in varying settings and affected the sample of participants included.

Despite these limitations, the findings from this study provide important direction for future research examining sensory processing in children with ASD across cultures and have important implications for professionals working with children with ASD from varying cultures. The study raises the need to discover both inherent and culturally mediated differences that may affect parents' perceptions of sensory processing differences between children with and without disabilities from different cultures. Further research is needed to determine the nature and extent of the influence that environment in general, and specifically the cultural environment, has on sensory processing.

\section{Acknowledgments}

This study was completed in partial fulfillment of Kristina G. Caron's requirements for a master of science degree in occupational therapy at Thomas Jefferson University.

\section{References}

American Occupational Therapy Association. (2008). Occupational therapy practice framework: Domain and process (2nd ed.). American Journal of Occupational Therapy, 62, 625-683. http://dx.doi.org/ 10.5014/ajot.62.6.625

American Psychiatric Association. (1994). Diagnostic and statistical manual of mental disorders (4th ed.). Washington, DC: Author.

Bennett, D. (1996). Comparison of sensory characteristics: Children with and without attention deficit disorder. Unpublished master's thesis, University of Kansas, Kansas City.

Ben-Sasson, A., Cermak, S. A., Orsmond, G. I., Tager-Flusberg, H., Carter, A. S., Kadlec, M. B., et al. (2007). Extreme sensory modulation behaviors in toddlers with autism spectrum disorders. American Journal of Occupational Therapy, 61, 584-592. http://dx.doi.org/10.5014/ajot.61.5.584

Ben-Sasson, A., Cermak, S. A., Orsmond, G. I., Tager-Flusberg, H., Kadlec, M. B., \& Carter, A. S. (2008). Sensory clusters of toddlers with autism spectrum disorders: Differences in affective symptoms. Journal of Child Psychology and Psychiatry, and Allied Disciplines, 49, 817-825. http://dx.doi. org/10.1111/j.1469-7610.2008.01899.x

Brock, J., Brown, C. C., Boucher, J., \& Rippon, G. (2002). The temporal binding deficit hypothesis of autism. Development and Psychopathology, 14, 209-224. http://dx. doi.org/10.1017/S0954579402002018

Canino, G., \& Alegría, M. (2008). Psychiatric diagnosis-Is it universal or relative to $\mathrm{cu}$ lture? Journal of Child Psychology and Psychiatry, and Allied Disciplines, 49, 237-250. http://dx.doi.org/10.1111/j.14697610.2007.01854.x

Cermak, S. A., \& Daunhauer, L. A. (1997). Sensory processing in the postinstitutionalized child. American Journal of Occupational Therapy, 51, 500-507. http://dx. doi.org/10.5014/ajot.51.7.500

Dunn, W. (1999). The Sensory Profile: User's manual. San Antonio, TX: Psychological Corporation.

Engel-Yeger, B. (2010). The applicability of the Short Sensory Profile for screening sensory 
processing disorders among Israeli children. International Journal of Rehabilitation Research, 33, 311-318. http://dx.doi. org/10.1097/MRR.0b013e32833abe59

Frith, U. (2003). Autism: Explaining the enigma. Oxford, England: Blackwell.

Gal, E., Cermak, S., \& Ben-Sasson, A. (2007). Sensory processing disorders in children with autism: Nature, assessment and intervention. In R. Gabriels \& D. Hill (Eds.), Growing up with autism: Working with school age children and adolescents (pp. 95-123). New York: Guilford.

Gal, E., Dyck, M., \& Passmore, A. (2002). Sensory differences and stereotyped movements in children with autism. Behaviour Change, 19, 207-219. http://dx.doi.org/ 10.1375/bech.19.4.207

Karno, M., \& Jenkins, J. H. (1993). Crosscultural issues in the course and treatment of schizophrenia. Psychiatric Clinics of North America, 16, 339-350.

Kientz, M. A., \& Dunn, W. (1997). A comparison of the performance of children with and without autism on the Sensory Profile. American Journal of Occupational Therapy, 51, 530-537. http://dx.doi.org/ 10.5014/ajot.51.7.530

Kirmayer, L. J. (2008). Culture and the metaphoric mediation of pain. Transcultural
Psychiatry, 45, 318-338. http://dx.doi. org/10.1177/1363461508089769

Kleinman, A. (1988). Rethinking psychiatry: From culture category to personal experience. New York: Free Press.

Lewis-Fernández, R. (1996). Cultural formulation of psychiatric diagnosis: Case No. 02. Diagnosis and treatment of Nervios and Ataques in a female Puerto Rican migrant. Culture, Medicine and Psychiatry, 20, 155-163. http://dx.doi.org/10. 1007/BF00115858

McIntosh, D. N., Miller, L. J., Shyu, V., \& Dunn, W. (1999). Overview of the Short Sensory Profile (SSP). In W. Dunn (Ed.), Sensory Profile: User's manual (pp. 5973). San Antonio, TX: Psychological Corporation.

Miller, L. J., Reisman, J. E., McIntosh, D. N., \& Simon, J. (2001). An ecological model of sensory modulation: Performance of children with Fragile X syndrome, autistic disorder, attention-deficit/hyperactivity disorder, and sensory modulation dysfunction. In S. Smith Roley, E. I. Blanche, \& R. C. Schaaf (Eds.), Understanding the nature of sensory integration with diverse populations (pp. 57-88). San Antonio, TX: Therapy Skill Builders.
Mottron, L., Burack, J. A., Stauder, J. E., \& Robaey, P. (1999). Perceptual processing among high-functioning persons with autism. Journal of Child Psychology and Psychiatry, and Allied Disciplines, 40, 203-211. http://dx.doi.org/10.1111/1469-7610. 00433

Ornitz, E. M. (1974). The modulation of sensory input and motor output in autistic children. Journal of Autism and Childhood Schizophrenia, 4, 197-215. http://dx.doi. org/10.1007/BF02115226

Rogers, S. J., Hepburn, S., \& Wehner, E. (2003). Parent reports of sensory symptoms in toddlers with autism and those with other developmental disorders. Journal of Autism and Developmental Disorders, 33, 631-642. http://dx.doi.org/10.1023/B: JADD.0000006000.38991.a7

Super, C. M., \& Harkness, S. (2002). Culture structures the environment for development. Human Development, 45, 270-274. http://dx.doi.org/10.1159/000064988

Tomchek, S. D., \& Dunn, W. (2007). Sensory processing in children with and without autism: A comparative study using the Short Sensory Profile. American Journal of Occupational Therapy, 61, 190-200. http://dx.doi.org/10.5014/ajot.61.2.190 